\title{
Common alien plants are more competitive than rare natives but not than common natives
}

\author{
Zhijie Zhang $^{1 *}$ (iD) and \\ Mark van Kleunen ${ }^{1,2}$ \\ ${ }^{1}$ Ecology, Department of Biology \\ University of Konstanz, 78464, \\ Konstanz, Germany \\ ${ }^{2}$ Zhejiang Provincial Key Laboratory \\ of Plant Evolutionary Ecology and \\ Conservation, Taizhou University, \\ Taizhou 318000, China
}

*Correspondence: E-mail:

zhijie.zhang@uni-konstanz.de

\begin{abstract}
Success of alien plants is often attributed to high competitive ability. However, not all aliens become dominant, and not all natives are vulnerable to competitive exclusion. Here, we quantified competitive outcomes and their determinants, using response-surface experiments, in 48 pairs of native and naturalised alien annuals that are common or rare in Germany. Overall, aliens were not more competitive than natives. However, common aliens (invasive) were, despite strong limitation by intraspecific competition, more competitive than rare natives. This is because alien species had higher intrinsic growth rates than natives, and common species had higher intrinsic growth rates than rare ones. Strength of interspecific competition was not related to status or commonness. Our work highlights the importance of including commonness in understanding invasion success. It suggests that variation among species in intrinsic growth rates is more important in competitive outcomes than inter- or intraspecific competition, and thus contributes to invasion success and rarity.
\end{abstract}

\section{Keywords}

annual plants, intra- and interspecific competition, Modern Coexistence Theory, niche, plant invasion, rarity.

\section{INTRODUCTION}

Over 13,000 plant species have established self-sustaining populations outside their natural ranges (van Kleunen et al. 2015; Pyšek et al. 2017), and the rise in the number of these alien species shows no sign of saturation (Seebens et al. 2017). Concerns over the impact of alien species (Vilà et al. 2011) have stimulated considerable interest in finding out what determines invasion success (van Kleunen et al. 2018). A primary hypothesis is that alien plant species are more competitive than native species (Baker 1965). Three meta-analyses on hundreds of experiments support this hypothesis (Vilà \& Weiner 2004; Kuebbing \& Nunez 2016; Golivets \& Wallin 2018). However, not all alien species become dominant (Williamson \& Fitter 1996), and not all native species are vulnerable to competitive exclusion (Levine et al. 2004). It is indeed debated whether common alien species, which are usually considered to be invasive, and common native species are successful because they follow the same rules and have similar characteristics (Jeschke \& Strayer 2008; Thompson \& Davis 2011; van Kleunen et al. 2011), such as a high resource-capture ability. In addition, results of previous studies on competition between alien and native species may be biased towards using common alien species (Hulme et al. 2013) and rare native species (Vilà \& Weiner 2004). Rigorous tests on competition between alien and native species that include both rare and common species are thus crucial to understanding the determinants of invasion success and rarity (van Kleunen et al. 2011).

Quantifying competitive ability of species is challenging. So far, there are more than 50 indices (Weigelt \& Jolliffe 2003), which fall into two main categories: competition outcomes tition (Gibson et al. 1999).
Competition outcomes, the first category, refer to which species will exclude or dominate over other species at the end point for the community. Most experiments inferred competitive outcomes from short-term studies (Aschehoug et al. 2016) or were restricted to a limited number of densities of competing species (Inouye 2001), which are unlikely to mimic real community dynamics (Hart et al. 2012). As a result, we might not be able to adequately extrapolate competitive outcomes between alien and native species from most previous studies.

The strength of interspecific competition, the other category, refers to the ability of species to tolerate and suppress other species. It is often used as a surrogate for competitive outcomes (Gibson et al. 1999). For example, Golivets \& Wallin (2018) and Kuebbing \& Nunez (2016) synthesized studies on the strength of interspecific competition. They concluded that alien species were more competitive than native species. Although the strength of interspecific competition is an important determinant of competitive outcomes, the two measures are not equivalent (Gibson et al. 1999; Aschehoug et al. 2016). Theoretical models suggest that species could become competitive through two other determinants: high intrinsic growth rates (i.e. growth rates in the absence of competition) and weak intraspecific competition (Chesson 2000; Hart et al. 2018; see Fig. 1 for hypothetical examples). Empirical support for this comes from a classic example of biological invasion: the Argentine ant (Linepithema humile). Individuals of this species do not exert stronger interspecific competition compared to native ants (Holway 1999). Nonetheless, loss of intraspecific competition increased population sizes of the Argentine ant and thus their competitive effect on native ants (Holway et al. 1998). However, few studies have examined the relative importance of the three determinants of competitive 
outcomes (intrinsic growth rates, intra- and interspecific competition; Godoy et al. 2014; Godoy \& Levine 2014; Chu \& Adler 2015). Moreover, we are not aware of any study considering these three determinants in combination with status (i.e. alien or native) and commonness of the interacting species.

Here, we conducted an experiment with a total of 17 alien $(n=9)$ and native $(n=8)$ annual species that are either common $(n=10)$ or rare $(n=7)$ in Germany. We described competition between 48 pairs of these alien and native species by growing 19,600 individuals in a response-surface design (Inouye 2001) in which we varied the density of both species of a pair independently. By parameterising a classical competition model with our data, we tested (1) whether the three theoretically justified determinants of competitive outcomes intrinsic growth rates, intra- and interspecific competition coefficients - were related to status and commonness. Then, we tested (2) whether alien species are more competitive than native species (i.e. competitive outcomes), and (3) whether the competitive outcomes were related to commonness of alien and native species.

\section{MATERIALS AND METHODS}

\section{Study species}

To increase our ability to generalize the results (van Kleunen et al. 2014), we initially selected 21 annual plant species that are either native or alien in Germany. We used annual species because they have short and simple life cycles that can be reasonably described by classical competition models (Levine \& HilleRisLambers 2009). Those 21 species represented four confamilial groups, each of which, ideally, included at least one common native species, one rare native species, one common alien species and one rare alien species. Because all species (except Cotula coronopifolia) mainly occur in grasslands and overlap in their distributions according to the FloraWeb database (Bundesamt für Naturschutz 2003), they are likely to interact with each other in nature. All alien species, including the rare ones, are naturalised (sensu Richardson et al. 2000) in Germany. We selected confamilial groups to control for phylogenetic correlations among species. However, due to difficulties in obtaining seeds and insufficient germination of some species, we could use only 17 of the 21 species (Table S1).

As commonness (or rarity) has multiple dimensions (Rabinowitz 1981), we selected species as being either common or rare based on two dimensions: occupancy frequency and local abundance level (Fig. S1; Table S1). Specifically, we assigned a species as common if it is widespread in Germany and is locally abundant, and as rare if it is not widespread in Germany and is not locally abundant. For the criterion of occupancy frequency, we used the range size of the species in Germany (calculated as the number of $130-\mathrm{km}^{2}$ grid cells occupied by the species, which was extracted from the FloraWeb database). We assigned a species as widespread if it occupies more than 500 out of all grid cells (i.e. 3000) in Germany. For the criterion of local abundance level, we assigned a species as abundant if it can form large groups (data extracted from the FloraWeb). It should be noted that the median number of grid cells of the rare and common species differed by more than one order of magnitude (108 vs. 1653 grid cells). So, they are quite different. Moreover, the most widespread rare species, Bromus japonicus, often occurs as isolated individuals, whereas the least widespread common species, Vulpia bromoides, often occurs in large groups. So, even though these two species were the most similar in occupancy frequency, they differed strongly in abundance level.

While we use here the terms common and rare as this applies both to native and alien species, the common alien (a)

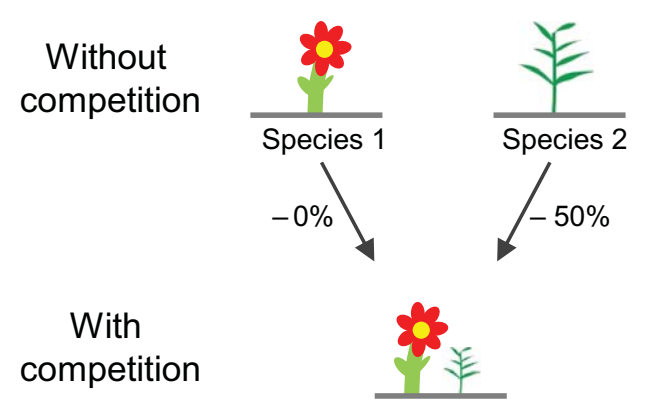

(b)

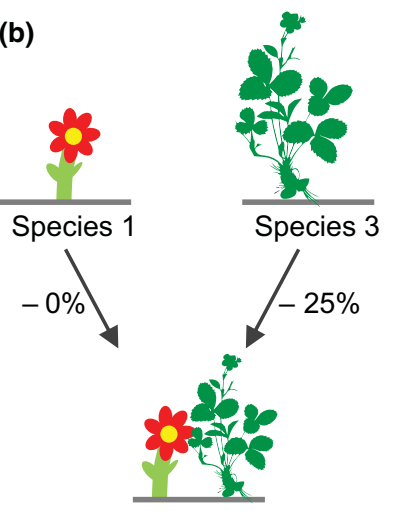

(c)

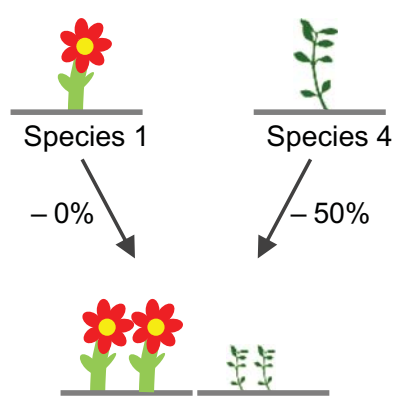

Figure 1 Three hypothetical examples illustrating the relationship between competitive outcome and its three determinants - intrinsic growth rate and strength of intra- and interspecific competition. In example (a), species 1 and species 2 have the same intrinsic growth rates, represented by the same sizes of the two species without competition. When in interspecific competition with each other, species 1 is unaffected, and species 2 has a $50 \%$ reduction in fitness (e.g. growth rate). In this situation, the competitive outcome is that species 1 has a higher fitness than species 2 when grown together (i.e. species 1 is more competitive). In example (b), species 3 has twice the intrinsic growth rate of species 1 , and when grown in interspecific competition with species 1 has a $25 \%$ reduction in fitness. In this situation, species 1 is less competitive than species 3 . In example (c), we include intraspecific competition. Species 4 and species 1 have the same intrinsic growth rates and are both unaffected by interspecific competition. However, when grown with intraspecific competition, species 1 is unaffected, whereas species 4 has a $50 \%$ reduction in fitness. In this situation, species 1 is more competitive than species 4 . Therefore, competitive outcomes might not always be well predicted by the strength of interspecific competition (i.e. arrows in examples a \& b) 
species can be considered as invasive alien species, and the rare alien species as non-invasive alien species. Still, there are multiple definitions of invasive species. Richardson et al. (2000) and Blackburn et al. (2011) proposed that invasive alien species need to overcome the barrier to spread in the landscape. The Convention on Biological Diversity (CBD 2000) and Levine et al. (2004) proposed that invasive alien species have negative impacts on other species. However, it is likely that a widespread and locally abundant species has a rapid spread rate and has negative impact; therefore, occupancy frequency and abundance level are important demographic dimension of invasiveness (Catford et al. 2016; van Kleunen et al. 2018).

\section{Experimental set-up}

The experiment, except the seed germination, took place outdoors in the botanical garden of the University of Konstanz, Germany $\left(47^{\circ} 41^{\prime} 31^{\prime \prime}\right.$ N, 9०10'44" E; 460 metres above sea level). On 5 or 12 June 2017, we sowed the 17 species separately into plastic trays filled with potting soil (Topferde $^{\circledR}$, Einheitserde Co., Sinntal-Altengronau, Germany; $\mathrm{pH}$ 5.8; $2.0 \mathrm{~g} \mathrm{~L}^{-1} \mathrm{KCl} ; 340 \mathrm{mg} \mathrm{L}^{-1} \mathrm{~N} ; 380 \mathrm{mg} \mathrm{L}^{-1} \mathrm{P}_{2} \mathrm{O}_{6} ; 420 \mathrm{mg} \mathrm{L}^{-1}$ $\mathrm{K}_{2} \mathrm{O} ; 200 \mathrm{mg} \mathrm{L}^{-1} \mathrm{~S} ; 700 \mathrm{mg} \mathrm{L}^{-1} \mathrm{Mg}$ ). To ensure that the different species were in similar developmental stages at the beginning of the experiment, we sowed the species at different times (Table S1), according to their germination speed known from previous (pilot) experiments. We then placed the trays with seeds in a greenhouse under natural light condition, with a temperature between 18 and $25^{\circ} \mathrm{C}$.

Based on the numbers of available seedlings, we used the 17 species to make 48 pairs to study pairwise competition between the alien and native plant species (Table S2). For each alien-native species pair, we transplanted the seedlings according to a response-surface experimental design (Inouye 2001), in which we had 20 different density combinations, such that the total density ranged from 4 via 8 and 12 to 16 plants per pot, and the frequency of each species from 0 via $0.25,0.5$ and 0.75 to 1 (Fig. 2). Response-surface designs mimic the dynamics of species populations across space and time (Hart et al. 2012) and allow more accurate parameterisation of mathematical models of competition than other designs, such as additive and substitution designs (Inouye 2001). Despite their various advantages, response-surface designs have been relatively little used (van Kleunen et al. 2006; Hart et al. 2012), because they are more labor intensive than other competition designs.

From 26 to 30 June 2017, we transplanted the seedlings, according to the design described above, into $3-\mathrm{L}$ plastic pots $(16 \times 16 \times 12 \mathrm{~cm})$ filled with potting soil $\left(\right.$ Topferde $\left.^{\circledR}\right)$. For individuals in bicultures, we arranged the two species in interspersed patterns (Fig. 2) to reduce the effect of intraspecific aggregation (Stoll \& Prati 2001). We replicated each density combination per pair of species twice, which resulted in a total of 1960 pots and 19,600 individuals. All pots were placed on plastic dishes to preserve water, and were separated by leaving $10 \mathrm{~cm}$ between pots to reduce interference. We replaced seedlings that died within 2 weeks after transplanting by new ones. We randomised the blocks (i.e. pairs) and pots (a) 5 levels of frequency of alien species

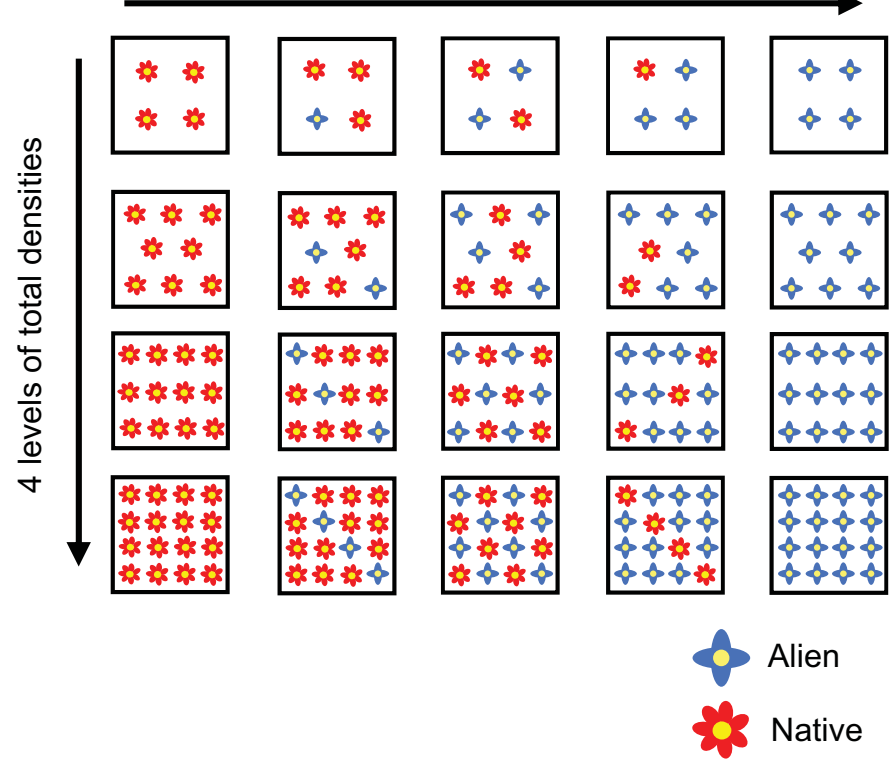

(b)

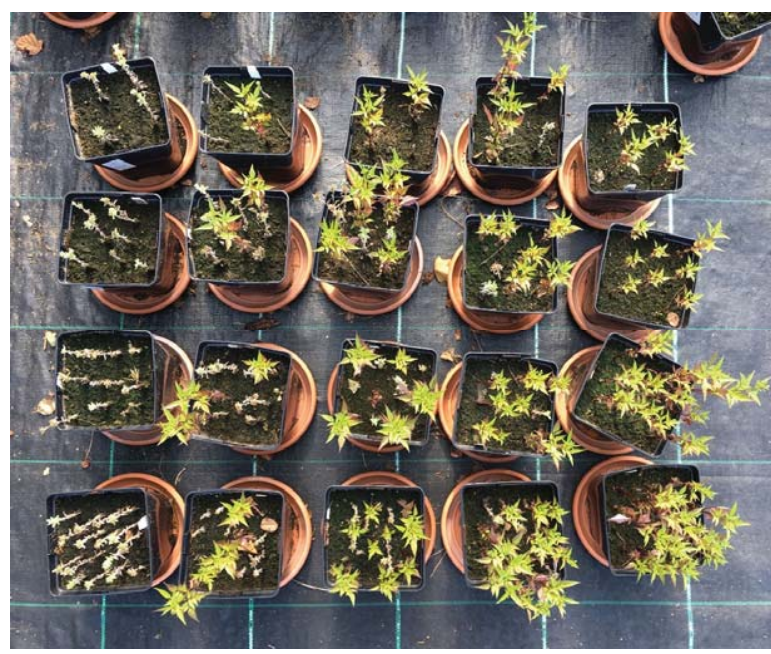

Figure 2 Graphical illustration (a) and an example (b) of the responsesurface design used for each pair of alien and native plant species. Each pair is grown in 20 density-frequency combinations. Aboveground biomass was measured for each individual separately. The example (b) shows the pair of the common alien Bidens frondosa and the rare native Filago pyramidata

within the blocks twice, once on 30 June 2017 and once on 14 August 2017. The plants were watered twice in 2018 summer to avoid severe drought stress.

\section{Measurements}

From 25 to 29 September 2017, we harvested half of the experiment (i.e. one of the two replicates). Aboveground biomass of each individual was harvested separately, dried at $70^{\circ} \mathrm{C}$ to constant weight and weighed to the nearest milligram. The other half of the experiment, we kept in the garden to measure the number of recruited offspring in the following year. We prevented seed dispersal by installing an open-top 
enclosure in each pot. The enclosure was made of white fabric and $50 \mathrm{~cm}$ tall, and reduced ambient light by c. 30\%. From 7 August to 5 September 2017 and for each pair of species, we installed enclosures for all pots when one or more individuals in that pair had started to fruit. We removed all enclosures in April 2018, and counted the number of recruits in each pot from 20 to 28 September 2018.

\section{Statistical analyses}

Intrinsic growth rates and competition coefficients

To describe competition between alien and native species in each pair, we fitted our data on aboveground biomass of individual plants to the following model:

$\ln \left(B_{i, t}\right)=\ln \left(\lambda_{i}\right)-\alpha_{i i} N_{i, t}-\alpha_{i j} N_{j, t}$.

This is a linearised version (by taking the natural log of both sides of the equation) of a modified Ricker competition model (Ricker 1954).

We chose the Ricker model because it has been widely used to link empirical data and theory, and its properties are well understood (Inouye 2001; Hart et al. 2012). In the equation, $B_{i, t}$ is the individual aboveground biomass of species $i$ in year $t$. $N_{i, t}$ and $N_{j, t}$ are the number of individuals of species $i$ and $j$ in year $t$ respectively. $\lambda_{i}$ is the intrinsic growth rate of species $i, \alpha_{i i}$ describes the per capita effect of species $i$ on itself (i.e. it is the intraspecific competition coefficient) and $\alpha_{i j}$ describes the per capita effect of species $j$ on species $i$ (i.e. the interspecific competition coefficient). Positive values of competition coefficients indicate competition among individuals, and negative values indicate facilitation. Therefore, $B_{i, t}$ is affected by the number of conspecific and heterospecific competitors (i.e. $\alpha_{i i} N_{i, t}$ and $\alpha_{i j} N_{j, t}$ ), and equals $\lambda_{i}$ in the absence of competition.

We used a linear mixed-effects model to fit the equation for each species per pair. We included the number of conspecific competitors and the number of heterospecific competitors as fixed effects, and pot as random effect to account for the nonindependence of individuals in the same pot. We used number of individuals at the end of the growing season of year $t$ rather than that at the beginning of the growing season. This is because most mortality happened early in the experiment. However, analyses using the number of individuals at the beginning of the growing season showed similar results (Table S3). This indicated that density-dependent mortality was not as important as growth in our experiment.

Ideally, $B_{i, t}$ should be $\frac{N_{i, t+1}}{N_{i, t}}$, the per capita population growth rate from one year to the next based on the number of recruits. However, it is usually difficult to link competition models with experimental data. In our experiment, only 8 of the 17 species consistently had recruits in the second year, which limited our ability to generate sufficient intrinsic growth rates and competition coefficients from the offspring recruitment data. Therefore, we used aboveground biomass of each individual at the end of the growing season (i.e. after 3 months of growth) instead. This means that the estimated intrinsic growth rates and competition coefficients are sensitive to the relationship between number of recruits and aboveground biomass. However, for the species with recruits, we found that the relationship between number of recruits and aboveground biomass was positively linear and not affected by status or commonness. We therefore believe that our estimates of intrinsic growth rate, intra- and interspecific competition, based on biomass data, are robust (Appendix S1).

To test whether intrinsic growth rates and intraspecific competition coefficients were related to status and commonness, we used linear mixed-effects models. The models treated status of target species (i.e. species $i$ ), commonness of target species and their interaction as fixed effects, and species (nested within family) of target species and identity of species pair (e.g. the alien species Bidens frondosa and the native species Brassica nigra formed the first pair in our study) as random effects. We did not include the information of competitor species (i.e. species $j$ ) as fixed or random effect, because we assumed that intrinsic growth rates and intraspecific competition were only determined by the target species itself. To test whether interspecific competition coefficients were related to status and commonness, we used another linear mixed-effects model. The model treated status of target species, commonness of target and competitor species and their interactions as fixed effects, and species of target and competitor species (each nested within family) and identity of pair as random effects. In these models, we included the inverse of the variance as weight, such that fitted parameters with larger variance would have less weight on the results.

\section{Competitive outcomes}

We tested competitive outcomes between alien and native plants with two different methods. One is based on population-level aboveground biomass (see below). The other is based on fitness differences sensu Chesson (Chesson 2000; Saavedra et al. 2017; Hart et al. 2018), which offers a longterm theoretical prediction. Because the intrinsic growth rates in our study are not based on recruitment data, we could only measure fitness difference qualitatively, rather than quantitatively. Nevertheless, the results based on fitness differences are similar to those based on population-level aboveground biomass. Therefore, we focus in the manuscript on the results based on population-level aboveground biomass, but we include the results of the fitness differences in Appendix S2.

We calculated $\ln R R_{k}$, the competitive outcome between alien and native plants in each of the biculture pots $(k)$ as:

$$
\ln R R_{k}=\ln \left(T B_{k \_a}\right)-\ln \left(T B_{k \_n}\right),
$$

where $T B_{k \_a}$ and $T B_{k n n}$ are the total aboveground biomass of alien and native species, respectively, in the biculture pot $k$. Positive values of $\ln R R_{k}$ indicate that alien species had higher biomass than native species in biculture $k$, and negative values indicate the opposite. Then, for each pair of species, we used a linear model with $\ln R R_{k}$ as the response variable and an intercept as the only explanatory variable. Therefore, a positive value of the intercept fitted for a pair indicates that, on average, the alien species in that pair had higher biomass than the native species across a wide range of density combinations (i.e. the alien species are more competitive than the native species), and a negative value of the intercept indicates the opposite.

Finally, to test competitive outcomes between alien and native species (i.e. intercepts fitted above for the 48 pairs), 
and whether competitive outcomes were explained by commonness of alien and native species, we used a linear mixedeffects model. The model treated commonness of alien and native species and their interaction as fixed effects, and species (nested within family) of alien and native species as random effects. We also included the inverse of the variance of the competitive outcomes as weight.

All analyses were conducted in R 3.4.0 (R Core Team 2017) with the lme4 package (Bates et al. 2015). Results were plotted with the plot function. To evaluate model variation explained by fixed effects, we used the $r 2 \mathrm{glmm}$ package (Jaeger et al. 2017). We assessed the significance of fixed effects with likelihood-ratio tests by comparing models with and without the effect of interest.

\section{RESULTS}

\section{Intrinsic growth rates and intra- and interspecific competition coefficients}

Alien species had significantly higher intrinsic growth rates (i.e. aboveground biomass in the absence of competition) than native species (Fig. 3a; Table $1 ; \chi^{2}=8.812, P=0.003$ ). Moreover, common species had significantly higher intrinsic growth rates than rare species (Fig. 3a; Table 1; $\chi^{2}=6.174$, $P=0.013)$. Intrinsic growth rates were not significantly affected by the interaction between commonness and status (Fig. 3a; Table 3).

Overall, intra- and interspecific competition coefficients $\left(\alpha_{i i}\right.$ and $\alpha_{i j}$ ) were positive (Fig. 3b,c), which indicate that both the intra- and interspecific interactions were competitive and not facilitative. Alien species experienced significantly stronger intraspecific competition than native species (Fig. 3b; Table 1; $\left.\chi^{2}=4.943, P=0.026\right)$. Although common and rare species on average did not differ in strength of intraspecific competition, we found a significant interaction between status and commonness (Fig. 3b; Table 1; $\chi^{2}=4.095, P=0.043$ ). For alien species, the common ones experienced stronger intraspecific competition than the rare ones, whereas for native species, the reverse was true (Fig. 3b).

Alien species tended to experience weaker interspecific competition from native species than native species did from alien species (Fig. 3c). However, this difference was not statistically significant (Table $1 ; \chi^{2}=1.975, P=0.160$ ). None of the other factors significantly affected the strength of interspecific competition (Table 1).

Intraspecific competition was stronger than interspecific competition (Fig. 3b,c; Appendix S3; $\chi 2=5.284, P=0.022$ ). This difference in strength between intra- and interspecific competition was larger in alien species than in native species (Fig. S6; Table S6; $\chi 2=4.678, P=0.030$ ). For alien species, this difference was larger in common than in rare ones, whereas for native species, the reverse was true (Fig. S6; Table S6; $\chi 2=6.487, P=0.011)$. We also found that status and commonness of species explained only a small amount of variation in intra- or interspecific competition, whereas they explained a large amount of variation in intrinsic growth rates $\left(R_{\sum}^{2}\right.$ in Table 1$)$

\section{Competitive outcomes}

When growing together, alien species overall tended to have higher biomass than native species across the different density combinations (Fig. 4). However, this difference was not statistically significant (Table $2 ; \chi^{2}=2.085, P=0.149$ ). Overall, the competitive outcome was more in favour of the alien species when the alien was common (Table $2 ; \chi^{2}=3.608, P=0.058$ ), and less in the alien's favour when the native was common (Table $2 ; \chi^{2}=3.450, P=0.063$ ). As a consequence, common alien species had higher biomass than rare natives, but similar biomass as common natives (Fig. 4). This indicates that common aliens were more competitive than rare natives. The same pattern was found for rare alien species competing with common and rare natives, but with a smaller magnitude of the differences (Fig. 4). In addition, we found that the higher competitive ability of common alien species over rare natives is mainly driven by intrinsic growth rates rather than by competition coefficients (Appendix S2).

\section{DISCUSSION}

We found that alien plant species did not achieve higher aboveground biomass when growing with native species. This indicates that alien and native species overall did not differ
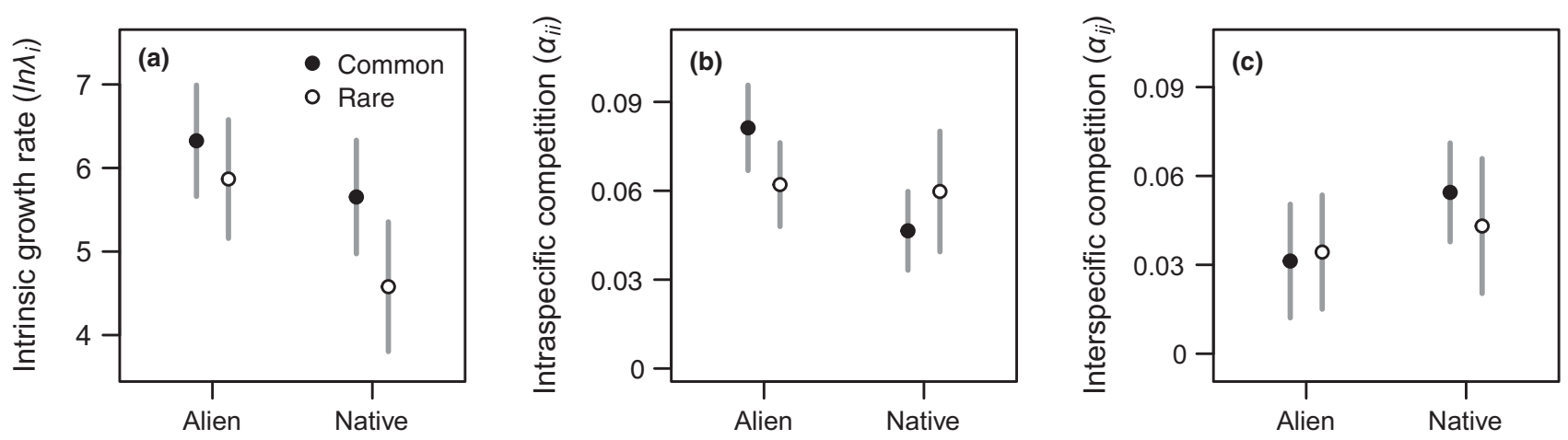

Figure 3 Mean intrinsic growth rates $\left(\mathrm{a}, \lambda_{i}\right)$ and intra- and interspecific competition coefficients $\left(\mathrm{b}, \alpha_{i i}\right.$; c, $\left.\alpha_{i j}\right)$ for common and rare alien and native plant species. Positive values of $\alpha_{i i}$ and $\alpha_{i j}$ indicate competitive interactions. Error bars represent $95 \%$ confidence intervals. Intrinsic growth rates $\left(\lambda_{i}\right)$, whose unit is milligram, was natural log-transformed. 
Table 1 Effects of status of target species (i.e. native or alien), commonness of target (and competitor) species and their interaction on intrinsic growth rates $\left(\lambda_{i}\right)$ and intra- and interspecific competition coefficients $\left(\alpha_{i i}\right.$ and $\left.\alpha_{i j}\right)$. Significant $(P<0.05)$ effects are in bold

\begin{tabular}{|c|c|c|c|c|c|c|}
\hline & \multicolumn{2}{|l|}{$\lambda_{i}$} & \multicolumn{2}{|l|}{$\alpha_{i i}$} & \multicolumn{2}{|l|}{$\alpha_{i j}$} \\
\hline & $\chi^{2}$ & $P$ & $\chi^{2}$ & $P$ & $\chi^{2}$ & $P$ \\
\hline Status (S) & 8.812 & 0.003 & 4.943 & 0.026 & 1.975 & 0.160 \\
\hline Commonness of target $\left(\mathrm{C}_{\mathrm{i}}\right)$ & 6.174 & 0.013 & 0.405 & 0.525 & 0.054 & 0.817 \\
\hline $\mathrm{S} \times \mathrm{C}_{\mathrm{i}}$ & 1.370 & 0.242 & 4.095 & 0.043 & 0.452 & 0.502 \\
\hline Commonness of competitor $\left(\mathrm{C}_{\mathrm{j}}\right)$ & - & - & - & - & 0.709 & 0.400 \\
\hline $\mathrm{S} \times \mathrm{C}_{\mathrm{j}}$ & - & - & - & - & 0.042 & 0.837 \\
\hline $\mathrm{C}_{\mathrm{i}} \times \mathrm{C}_{\mathrm{j}}$ & - & - & - & - & 0.625 & 0.429 \\
\hline $\mathrm{S} \times \mathrm{C}_{\mathrm{i}} \times \mathrm{C}_{\mathrm{j}}$ & - & - & - & - & 0.003 & 0.956 \\
\hline Random effects & $\mathrm{SD}$ & & $\mathrm{SD}$ & & $\mathrm{SD}$ & \\
\hline Pair & 0.193 & & 0.005 & & 0.005 & \\
\hline Species of target (nested in family) & 0.533 & & 0.002 & & 0.002 & \\
\hline Family of target & 0.398 & & 0.000 & & 0.000 & \\
\hline Species of competitor (nested in family) & - & & - & & 0.017 & \\
\hline Family of competitor & - & & - & & 0.000 & \\
\hline Residual & 0.465 & & 0.381 & & 0.367 & \\
\hline Variation explained by fixed effects, $R_{\Gamma}^{2}$ & $43.9 \%$ & & $6.7 \%$ & & $3.0 \%$ & \\
\hline
\end{tabular}

For $\lambda_{i}$ and $\alpha_{i i}$, information of competitor (i.e. species $j$ ) was not included in the model, because we assumed that $\lambda_{i}$ and $\alpha_{i i}$ were only determined by the target species per se.

markedly in their competitive abilities. However, common alien species were more competitive than rare natives. For the three determinants of competitive outcomes (i.e. competitive ability), we found that, although common alien species experienced stronger intraspecific competition than native species, alien and common species had higher intrinsic growth rates (i.e. growth rates in the absence of competition) than native and rare species respectively. Finally, the strength of interspecific competition was not related to status or commonness of the species. So, our results suggest that although alien and native plant species do not generally differ in competitive

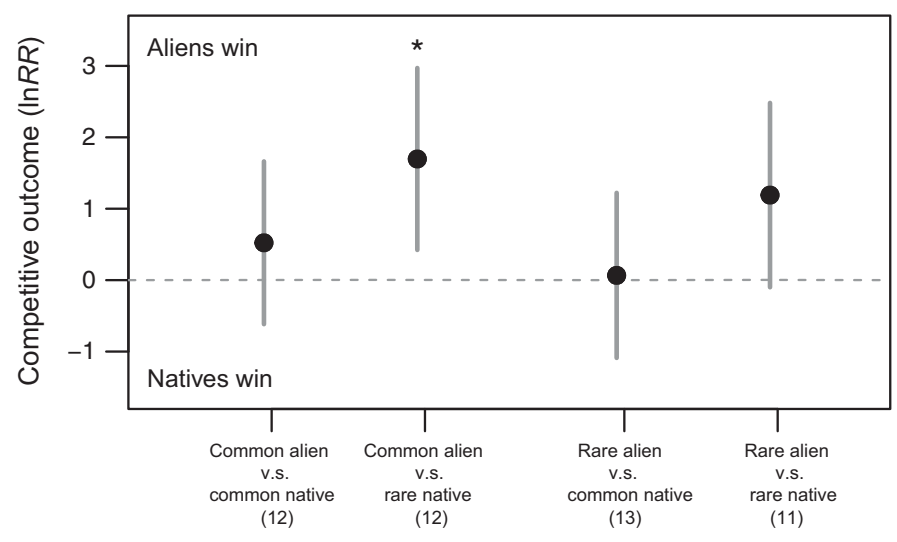

Figure 4 Mean values of competitive outcomes between alien and native plant species (i.e. mean values of $\ln R R_{k}$ ) and their relationship with commonness of alien and native species. Positive values of competitive outcomes indicate that alien species have higher biomass than the native species they are growing with across a wide range of density combinations. Error bars represent 95\% confidence intervals. The asterisk $(*)$ indicates that common alien species are significantly more competitive (i.e. dominate in bicultures) than rare native species. Numbers in parentheses indicate sample sizes (i.e. number of species pairs) for four categories abilities, the common aliens have higher competitive abilities than the rare natives, mostly due to higher intrinsic growth rates.

\section{Competitive abilities of alien and native plant species}

On average, alien species were not more competitive than native species. Therefore, our results contradict those of two recent meta-analyses which found that alien species were more competitive than native species (Kuebbing \& Nunez 2016; Golivets \& Wallin 2018). However, in the two meta-analyses, approximately $90 \%$ of the alien species were invasive plants. Therefore, the meta-analyses likely revealed the high competitive ability of invasive plants, rather than of alien plants in general (Guerin et al. 2018). In line with this, we found that

Table 2 Effects of commonness of alien species, commonness of native species and their interaction on competitive outcomes (i.e. which species have higher aboveground biomass in bicultures across different density combinations). Significant differences were not found. Marginally significant $(0.05 \leq P<0.1)$ effects are shown in italics

\begin{tabular}{|c|c|c|}
\hline & $\chi^{2}$ & $P$ \\
\hline Intercept $^{\dagger}$ & 2.085 & 0.149 \\
\hline Commonness of alien $\left(\mathrm{C}_{\mathrm{a}}\right)$ & 3.608 & 0.058 \\
\hline Commonness of native $\left(\mathrm{C}_{\mathrm{n}}\right)$ & 3.545 & 0.063 \\
\hline $\mathrm{C}_{\mathrm{a}} \times \mathrm{C}_{\mathrm{n}}$ & 0.043 & 0.835 \\
\hline Random effects & $\mathrm{SD}$ & \\
\hline Species of alien (nested in family) & 0.263 & \\
\hline Family of alien & 0.810 & \\
\hline Species of native (nested in family) & 0.847 & \\
\hline Family of native & 0.000 & \\
\hline Residual & 0.360 & \\
\hline Variation explained by fixed effects, $R_{\sum}^{2}$ & $36.4 \%$ & \\
\hline
\end{tabular}

*The intercept term indicates the competitive outcome between alien and native species irrespective of commonness. 
common alien species, which can be considered as invasive species, were more competitive than rare natives. This highlights the importance of including commonness of alien and native species in studies aiming to understand invasion success. Moreover, the two meta-analyses did not measure competitive ability directly. Instead, they used the strength of interspecific competition as a surrogate. This might be insufficient, because competitive ability also depends on two other determinants: the strength of intraspecific competition and intrinsic growth rates. Neither of these two determinants was directly measured in the two meta-analyses. Our study, by measuring competitive ability empirically (Fig. 4) and theoretically (Appendix S2), provides a robust test for differences in competitive ability.

It is also worth noting that rare alien species were as competitive as common natives, and tended to be more competitive than rare natives. Therefore, rare alien species also have the potential to exclude rare native species, which implies that more alien species might become dominant in the future, particularly if natives suffer more from climate change than aliens do (Haeuser et al. 2017; Haeuser et al. 2018). The higher competitive ability of rare alien species compared to rare natives can be due to several reasons. First, all alien species used in our study are naturalised alien ones, which is a small proportion (usually 5-20\%; Williamson \& Fitter 1996) of introduced alien species. Therefore, even those rare alien species might not be a random sample of the global flora. Second, alien species are likely to be released from their natural enemies (Keane \& Crawley 2002; Chun et al. 2010). If this enemy release hypothesis holds for rare alien species, they can gain advantages over rare native species.

Alien species can only become common if they have had sufficient time to reproduce and spread in the landscape. Therefore, it could be that some of the rare alien species are not dominant yet because they were introduced only recently. However, this is likely not the case in our study system, because the common and rare alien species did not differ in their residence time (Appendix S4). Furthermore, adding residence time as a covariate in our models did not significantly affect the differences in competitive ability between alien and native species (Appendix S4). Therefore, we speculate that the common alien species became abundant and widespread because they have stronger competitive abilities and consequently rapid spread rates.

\section{Three determinants of competitive ability}

We found that alien and common species had higher intrinsic growth rates than native and alien species respectively. This is in line with the results of a meta-analysis (van Kleunen et al. 2010) and an empirical study that considers both commonness and status (Dawson et al. 2012). Our finding suggests that naturalised alien and common species, at least for annual species, have a fast life history (i.e. are r-selected; Pianka 1970), such that they could quickly achieve massive populations when they arrive in non-competitive environments (Rejmánek \& Richardson 1996). In addition, high intrinsic growth rates of alien species, especially for common aliens, could provide rapid recovery from disturbance (Haddad et al. 2008).
Overall, this would explain the frequent association between invasion success and disturbance (Davis et al. 2000), and the observation that anthropogenic environments are the major donors of naturalised alien species (Kalusová et al. 2017).

In contrast to the results of two recent meta-analyses, which found that alien species experienced weaker strength of interspecific competition than native species (Kuebbing \& Nunez 2016; Golivets \& Wallin 2018), we found no significant difference in interspecific competition experienced by native and alien species. Possibly, although we measured interspecific competition with a more accurate approach (i.e. response-surface design) and used an unprecedented large number of species pairs (48), the number is still lower than the numbers of species pairs used in the two meta-analyses mentioned above, and we thus had a lower statistical power. In addition, the two meta-analyses included both annual and perennial species, whereas we only used annuals. Because perennial species live longer, they may compete with other species more often than annuals do. If that is the case, a better ability to tolerate or suppress other species might make it easier for perennial alien species to persist and to exclude natives.

Interestingly, alien species, especially the common ones, experienced stronger intraspecific competition than native species. Together with our finding that intraspecific competition was greater than interspecific competition (which indicates niche differences sensu Chesson 2000; Appendix S3), common alien species should be disadvantaged by severe intraspecific competition when they become dominant in communities. Although this is true, intrinsic growth rates were high enough to ensure that common aliens could dominate in our experimental mesocosms. This illustrates that for a proper prediction of competitive outcomes, one requires data on the combination of intrinsic growth rates, intra- and interspecific competition. The reason why common alien species experience strong intraspecific competition is not known. However, we speculate that it might arise from a growth - intraspecific competition trade-off. For example, species with large sizes would experience severe light competition due to crowding in monoculture. This trade-off is supported by a recent study (Dostál et al. 2019), but still rarely tested and deserves further investigation.

\section{Potential limitations and future directions}

We performed our experiment outdoors in order to have more natural conditions. However, we grew the plants on a relatively nutrient-rich commercial potting soil. This could potentially have biased our results. A high nutrient level of the potting soil can turn competition for multiple nutrients into competition for light (Hautier et al. 2009), which is one-dimensional and thereby leads to competitive exclusion more easily. Therefore, in nature, common alien species might not always exclude rare native species if multiple nutrients are limited. Ideally, one would therefore do competition experiments under a range of different nutrient conditions. Moreover, although we chose relatively large pots $(3 \mathrm{~L})$, they are still likely to have limited root growth, particularly of large plant species (Poorter et al. 2012). Given that in our experiment, common alien species were found to be larger than rare native 
species, the common alien ones might have suffered more from root limitation. So, it could be that in nature, common alien species might be released from root growth limitation and thereby become even more competitive than the rare natives.

It should be noted that only small amounts of variation in the intra- and interspecific competition coefficients were explained by the status and commonness of the species (Table 1). Of the random factors in the models analysing the competition coefficients, the variance components related to the identities of the species were also relatively small, whereas the variance component of the residuals was large. This may indicate that other factors, such as intraspecific variability and environmental stochasticity, can strongly affect the magnitude and direction of intra- and interspecific competition coefficients.

\section{CONCLUSIONS}

We demonstrated that naturalised alien plant species were not more competitive than native species after accounting for the effect of commonness. However, common alien species were more competitive than rare native species, and this might be an important cause of loss of rare native species. More importantly, our results suggest that, although high intrinsic growth rates would sometimes come at the cost of strong intraspecific competition, they are the major driver of high competitive ability of common alien species, and thus might play an essential role in both invasion success and rarity. Finally, most pairwise competition experiments aimed to determine the strength of interspecific competition (Kuebbing \& Nunez 2016; Golivets \& Wallin 2018), which is insufficient to predict competitive outcomes as suggested by our results. Therefore, experiments examining intrinsic growth rates and intraspecific competition are urgently needed if we are to predict coexistence between native and alien species more definitively.

\section{ACKNOWLEDGEMENTS}

We thank O. Ficht, M. Fuchs, S. Gommel, Y. Liu, E. Mamonova, V. Pasqualetto, C. Rabung, B. Rüter, H. Vahlenkamp and E. Werner for practical assistance; and W. Goymann, R. Rohr, J. Levine, J. Gurevitch and three anonymous referees for helpful comments. Z.Z. acknowledges funding from the China Scholarship Council (201606100049) and support from the International Max Planck Research School for Organismal Biology.

Z.Z. conceived the idea. Z.Z. and M.v.K designed the experiment. Z.Z. performed the experiment. Z.Z. analyzed the data and wrote the manuscript with input from M.v.K.

\section{REFERENCES}

Aschehoug, E.T., Brooker, R., Atwater, D.Z., Maron, J.L. \& Callaway, R.M. (2016). The Mechanisms and consequences of interspecific competition among plants. Ann. Rev. Ecol. Syst., 47, 263-281.

Baker, H. (1965). Characteristics and modes of origin of weeds. In The Genetics of Colonizing Species. (eds Baker, H., Stebbins, G.). Academic Press, New York, pp. 147-172.

Bates, D., Mächler, M., Bolker, B. \& Walker, S. (2015). Fitting linear mixed-effects models using lme4. J. Stat. Softw., 67, 48.

Blackburn, T.M., Pysek, P., Bacher, S., Carlton, J.T., Duncan, R.P., Jarosik, V. et al. (2011). A proposed unified framework for biological invasions. Trends Ecol. Evol., 26, 333-339.

Bundesamt für Naturschutz. (2003). FloraWeb: Daten und Informationen zu Wildpflanzen und zur Vegetation Deutschlands. Available at: http:// www.floraweb.de/ Last accessed 20, October 2018.

Catford, J.A., Baumgartner, J.B., Vesk, P.A., White, M., Buckley, Y.M. \& McCarthy, M.A. (2016). Disentangling the four demographic dimensions of species invasiveness. J. Ecol., 104, 1745-1758.

CBD (Conv. Biol. Divers.). (2000). Alien species that threaten ecosystems, habitats or species. Decision $\mathrm{V} / 8$ of the United Nations Environment Programme/Convention of Biological Diversity/Conference of the Parties 5, Secretariat of the CBD. Available, Nairobi, Kenya. Available at: https://www.cbd.int/decision/cop/?xml:id $=7150$. Last accessed 15, March 2019.

Chesson, P. (2000). Mechanisms of maintenance of species diversity. Ann. Rev. Ecol. Syst., 31, 343-366.

Chu, C. \& Adler, P.B. (2015). Large niche differences emerge at the recruitment stage to stabilize grassland coexistence. Ecol. Monogr., 85, 373-392.

Chun, Y.J., van Kleunen, M. \& Dawson, W. (2010). The role of enemy release, tolerance and resistance in plant invasions: linking damage to performance. Ecol. Lett., 13, 937-946.

R Core Team (2017). R: A Language and Environment for Statistical Computing. R Foundation for Statistical Computing, Vienna, Austria. Available at: http://www.R-project.org/. Last accessed 2, May 2017.

Davis, M.A., Grime, J.P. \& Thompson, K. (2000). Fluctuating resources in plant communities: a general theory of invasibility. J. Ecol., 88, 528534.

Dawson, W., Fischer, M. \& van Kleunen, M. (2012). Common and rare plant species respond differently to fertilisation and competition, whether they are alien or native. Ecol. Lett., 15, 873-880.

Dostál, P., Tasevová, K. \& Klinerová, T. (2019). Linking species abundance and overyielding from experimental communities with niche and fitness characteristics. J. Ecol., 107, 178-189.

Gibson, D., Connolly, J., Hartnett, D. \& Weidenhamer, J. (1999). Designs for greenhouse studies of interactions between plants. J. Ecol., $87,1-16$.

Godoy, O. \& Levine, J.M. (2014). Phenology effects on invasion success: insights from coupling field experiments to coexistence theory. Ecology, 95, 726-736.

Godoy, O., Kraft, N.J.B. \& Levine, J.M. (2014). Phylogenetic relatedness and the determinants of competitive outcomes. Ecol. Lett., 17, 836-844.

Golivets, M. \& Wallin, K.F. (2018). Neighbour tolerance, not suppression, provides competitive advantage to non-native plants. Ecol. Lett., 21, 745-759.

Guerin, G.R., Martín-Forés, I., Sparrow, B. \& Lowe, A.J. (2018). The biodiversity impacts of non-native species should not be extrapolated from biased single-species studies. Biodiver. Conserv., 27, 785-790.

Haddad, N.M., Holyoak, M., Mata, T.M., Davies, K.F., Melbourne, B.A. \& Preston, K. (2008). Species' traits predict the effects of disturbance and productivity on diversity. Ecol. Lett., 11, 348-356.

Haeuser, E., Dawson, W. \& van Kleunen, M. (2017). The effects of climate warming and disturbance on the colonization potential of ornamental alien plant species. J. Ecol., 105, 1698-1708.

Haeuser, E., Dawson, W. \& van Kleunen, M. (2018). Introduced garden plants are strong competitors of native and alien residents under simulated climate change. J. Ecol., 107, 1328-1342. 
Hart, S.P., Burgin, J.R. \& Marshall, D.J. (2012). Revisiting competition in a classic model system using formal links between theory and data Ecology, 93, 2015-2022.

Hart, S.P., Freckleton, R.P. \& Levine, J.M. (2018). How to quantify competitive ability. J Ecol, 106, 1902-1909.

Hautier, Y., Niklaus, P.A. \& Hector, A. (2009). Competition for light causes plant biodiversity loss after eutrophication. Science, 324, 636-638.

Holway, D.A. (1999). Competitive mechanisms underlying the displacement of native ants by the invasive argentine ant. Ecology, 80, 238-251.

Holway, D.A., Suarez, A.V. \& Case, T.J. (1998). Loss of intraspecific aggression in the success of a widespread invasive social insect. Science, 282, 949-952.

Hulme, P.E., Pysek, P., Jarosik, V., Pergl, J., Schaffner, U. \& Vila, M. (2013). Bias and error in understanding plant invasion impacts. Trends Ecol. Evol., 28, 212-218.

Inouye, B.D. (2001). Response surface experimental designs for investigating interspecific competition. Ecology, 82, 2696-2706.

Jaeger, B.C., Edwards, L.J., Das, K. \& Sen, P.K. (2017). An R2 statistic for fixed effects in the generalized linear mixed model. J. Appl. Stat., 44, 1086-1105.

Jeschke, J.M. \& Strayer, D.L. (2008). Are threat status and invasion success two sides of the same coin? Ecography, 31, 124-130.

Kalusová, V., Chytrý, M., van Kleunen, M., Mucina, L., Dawson, W., Essl, F. et al. (2017). Naturalization of European plants on other continents: The role of donor habitats. PNAS, 114, 13756-13761.

Keane, R.M. \& Crawley, M.J. (2002). Exotic plant invasions and the enemy release hypothesis. Trends Ecol. Evol., 17, 164-170.

van Kleunen, M., Andre Stephan, M. \& Schmid, B. (2006). [CO2]- and density-dependent competition between grassland species. Glob. Chang Biol., 12, 2175-2186.

van Kleunen, M., Weber, E. \& Fischer, M. (2010). A meta-analysis of trait differences between invasive and non-invasive plant species. Ecol. Lett., 13, 235-245.

van Kleunen, M., Dawson, W. \& Dostal, P. (2011). Research on invasiveplant traits tells us a lot. Trends Ecol. Evol., 26, 317-317.

van Kleunen, M., Dawson, W., Bossdorf, O. \& Fischer, M. (2014). The more the merrier: multi-species experiments in ecology. Basic Appl. Ecol., 15, 1-9.

van Kleunen, M., Dawson, W., Essl, F., Pergl, J., Winter, M., Weber, E. et al. (2015). Global exchange and accumulation of non-native plants. Nature, 525, 100-103.

van Kleunen, M., Bossdorf, O. \& Dawson, W. (2018). The ecology and evolution of alien plants. Ann. Rev. Ecol. Syst., 49, 25-47.

Kuebbing, S.E. \& Nunez, M.A. (2016). Invasive non-native plants have a greater effect on neighbouring natives than other non-natives. Nat. Plants, 2, 16134.

Levine, J.M. \& HilleRisLambers, J. (2009). The importance of niches for the maintenance of species diversity. Nature, 461, 254-U130.

Levine, J.M., Adler, P.B. \& Yelenik, S.G. (2004). A meta-analysis of biotic resistance to exotic plant invasions. Ecol. Lett., 7, 975-989.
Pianka, E.R. (1970). On r- and K-selection. Am. Nat., 104, 592-597.

Poorter, H., Bühler, J., van Dusschoten, D., Climent, J. \& Postma, J.A. (2012). Pot size matters: a meta-analysis of the effects of rooting volume on plant growth. Funct. Plant Biol., 39, 839-850.

Pyšek, P., Pergl, J., Essl, F., Lenzner, B., Dawson, W., Kreft, H. et al. (2017). Naturalized alien flora of the world. Preslia, 89, 203-274.

Rabinowitz, D. (1981). Seven forms of rarity. In: The Biological Aspects of Rare Plant Conservation (ed Synge, H.). John Wiley and Sons, Chichester, UK, pp. 205-217.

Rejmánek, M. \& Richardson, D.M. (1996). What attributes make some plant species more invasive? Ecology, 77, 1655-1661.

Richardson, D.M., Pyšek, P., Rejmánek, M., Barbour, M.G., Panetta, F.D. \& West, C.J. (2000). Naturalization and invasion of alien plants: concepts and definitions. Divers. Distrib., 6, 93-107.

Ricker, W.E. (1954). Stock and Recruitment. J. Fish. Res. Board can., 11, 559-623.

Saavedra, S., Rohr, R.P., Bascompte, J., Godoy, O., Kraft, N.J.B. \& Levine, J.M. (2017). A structural approach for understanding multispecies coexistence. Ecol. Monogr., 87, 470-486.

Seebens, H., Blackburn, T.M., Dyer, E.E., Genovesi, P., Hulme, P.E., Jeschke, J.M. et al. (2017). No saturation in the accumulation of alien species worldwide. Nat. Commun., 8, 14435.

Stoll, P. \& Prati, D. (2001). Intraspecific aggregation alters competitive interactions in experimental plant communities. Ecology, 82, 319-327.

Thompson, K. \& Davis, M.A. (2011). Why research on traits of invasive plants tells us very little. Trends Ecol. Evol., 26, 155-156.

Vilà, M. \& Weiner, J. (2004). Are invasive plant species better competitors than native plant species? - Evidence from pair-wise experiments. Oikos, 105, 229-238.

Vilà, M., Espinar, J.L., Hejda, M., Hulme, P.E., Jarosik, V., Maron, J.L. et al. (2011). Ecological impacts of invasive alien plants: a metaanalysis of their effects on species, communities and ecosystems. Ecol. Lett., 14, 702-708.

Weigelt, A. \& Jolliffe, P. (2003). Indices of plant competition. J. Ecol., 91, $707-720$.

Williamson, M. \& Fitter, A. (1996). The varying success of invaders. Ecology, 77, 1661-1666. 